\title{
Assessing of use of the Internet for personal reasons at lessons at school: A Validation of the Cyberloafing Scale
}

\author{
Nadezhda Sivrikova ${ }^{1}{ }^{*}$, Svetlana Roslyakova ${ }^{1}$, Nadezhda Sokolova ${ }^{1}$ and Elena Moiseeva ${ }^{1}$ \\ South Ural State Humanitarian Pedagogical University, Department of Social Work, \\ Pedagogy and Psychology, 454080 Chelyabinsk, Russia
}

\begin{abstract}
Emergence of a possibility of Internet access at school bears new opportunities and risks too. The tendency to growth of number of the pupils Internet use for non-class-related purposes in the classroom (Cyberloafing) causes concern. Studying of this new phenomenon at the Russian school is complicated due to the lack of reliable and valid techniques. Therefore, adaptation of a scale of a cyberloafing of Y. Akbulut, etc. became an objective of this research. We translated into Russian of 29 items of a technique which were estimated by school students by means of 5-point Laykert scales. Results of application of a scale showed that its items form 5 factors. These are online shopping, accessing online content, activity on social networks, sharing information, socialization. The items of a factor of playing online games did not receive confirmation of validity and internal consistency. They need to be reconsidered. The received factors have sufficient reliability (the Cronbach's alpha $(\alpha)$ values of all the factors range from 0.77 to 0.881 ). Work makes a contribution to studying of a cyberloafing at school.
\end{abstract}

\section{Introduction}

The last decades are connected with significant changes in life of people. Process of digital transformation of society (digitalization) strengthened a gap between generations [1] and essentially changed a landscape of education [2]. Improvement of digital devices with access to global network and distribution of the high-speed Internet facilitated access for children to new technologies. As a result, the age of begining Internet use of children decreased up to 4-6 months [3,4]. Children begin to show interest to social to networks from 9 years old [5]. 93\% of teenagers at the age of 12-16 years are users of several of social to networks [6]. There is a new term for designation of this generation "digital natives" [7,8]. Researchers consider that the modern generation of school students is focused on use of information technologies everywhere including in a class. Recently such behavior becomes a debatable subject. Researchers consider positive and negative results of a digitalization of education. It is noted that use of digital technologies in a class leads to strengthening of motivation of pupils $[2,8,9]$, to formation of skills of reading and

* Corresponding author: bobronv@,cspu.ru 
language proficiency [2]. However, there are also negative effects of use of digital devices (tablets, smartphones, laptops) in a class during a lesson. Such activity poses a serious threat of understanding by the school student of a training material [10], reduces ability of reproduction of the passable material [2] and is negatively connected with academic performance [11]. Domination in network of entertaining content distracts school students from the solution of educational tasks [12].

Teachers recognize not realness of expectations that school students will use during a lesson digital devices only in the educational purposes. Researchers consider that Cyberloafing (Internet use during a lesson for personal non-class-related purposes) represents a problem which only amplifies recently [2]. The review of literature on this subject showed that: 1) much attention is paid to a cyberloafing in a business, but not in an education system; 2) foreign researches on a cyberloafing in the educational environment are pilot studs, and in Russia are not conducted. It is connected with lack of methods of measurement of a cyberloafing in Russian language and with the low level of understanding of scale of distribution of this phenomenon at modern school. Therefore, the purpose of our work consisted in adaptation of a scale of a cyberloafing 4for Russian-language selection of school students and the analysis of prevalence of this phenomenon among pupils.

\section{Theoretical background}

\subsection{Cyberloafing}

The term a cyberloafing appeared in scientific literature at the beginning of the 2000th years. Cyberloafing is among such behaviors which was formerly defined as defined as employee's use of companies' internet access for personal (non-work related) purposes during work hours [13]. With development of technologies the field of the term extended. Use of any digital - technologies and mobile devices for personal reasons in a workplace was added to it $[14,15,16]$. Besides cyberloafing there are many terms explaining the same or similar behavior like non-work related computing, cyberslacking, cyberbludging, on-line loafing, internet deviance, problematic internet use, personal web usage at work, internet dependency, internet abuse, internet addiction and internet addiction disorder [17]. All of them focus attention on the employees using technological devices to pursue the personal aims instead of the solution of working tasks. Thus, the cyberloafing represents a special form of leaving which is implemented due to use of information technologies [16]. It causes serious concerns to heads of the organizations since creates numerous problems [15]. Researchers consider a cyberloafing as a type of the counterproductive (CWB) deviant behavior in a workplace $[16,18,19,20]$.

It is necessary to recognize that cyberloafing differs from classical options of the counterproductive behavior, such as theft at work, sexual harassments, intended delay, etc. [21]. It is connected with boredom in a workplace [21] and has positive effects, such as minimization of a stress, improvement of $\operatorname{mood}[17,20,22]$ and self-education [23].

\subsection{Cyberloafing in Academic sphere}

The review of the researches devoted to a cyberloafing shows that this phenomenon is actively studied in a business sphere [13, 15, 22, 24, 25, 26]. However, it is present at other spheres, for example at the academic system [2, 11, 22, 24, 27, 28, 29]. Researchers note that the sector of education belongs to one of those areas where the Internet is used most intensively [30, 31]. Distribution of mobile technologies and wireless networks brought in an education system not only new opportunities, but risks too. One of such threats is use of 
information and communication technologies on occupations for the solution of the tasks which are not connected with training - a cyberloafing [31]. Researchers consider cyberloafing as a barrier to successful integration of information and communication technologies on educational sphere [29]. 2 parties can act as subjects of a cyberloafing in education. These are teachers and pupils. Empirical data specify that students are more subject to a cyberloafing, than teachers [32].

Phenomenon of cyberloafing among teachers is considered as a hindrance in performance of professional duties which is connected with side effects of use of devices with Internet access. Researchers assume that cyberloafing can be one of symptoms of professional burning out of the teacher [22]. In general, this phenomenon is insufficiently studied at the moment.

The researches of cyberloafing pay much attention to pupils (school and university students). First of all, the reasons not-training of use of technologies at a lesson are analyzed. It is motivation, the purposes, the teacher, an environment, time [33], the maintenance of a course, the identity of the pupil and possession of information technologies $[22,27]$. Researches showed that psychosocial representations, installations and the strategy of training, but not educational motivation influence on cyberloafing behavior at a lesson [11]. Class level, family income and the residence appeared among environment factors which are connected with the cyberloafing level of students [26].

Researchers come to a conclusion that cyberloafing represents harmful derivation in a class, but can have positive effect, under certain conditions. For example, cyberloafing can be means of restoration of forces [11].

\subsection{Cyberloafing Scales}

Use of the general methods of a research (questionnaire and interview form) is admissible at the initial stages of studying of the new social phenomenon. Deeper studying of a cyberloafing demands development of special measurement tools. Now foreign researchers use a wide range of scales of a cyberloafing [14]. Among them are the most widespread [14]: Cyberloafing scale by V.K.G. Lim [13] and V. K. G. Lim and T.S.H. Teo's cyberloafing scales [34]. These techniques measure 2 types of behavior: browsing and emailing activity. T. K. Coskun and S. Gokcearslan [35] showed that most often studies of cyberloafing in education lean on scales, the developed A.L. Blanchard and C. A. Henle [36] and Y. Akbulut et al. [24]. The first of them reveals expressiveness of two forms of a cyberloafing: minor cyberloafing (e.g., sending and receiving personal email at work) and serious cyberloafing (e.g., online gambling, surfing adult oriented web sites, participating in chat rooms and reading blogs.) [36]. The second scale allows to estimate expressiveness of 5 forms of behavior: sharing ( $\mathrm{Sa}$ ), shopping (So), real-time updating (Rtu), accessing online content (Aoc) and gaming or gambling (Gg) [2].

Besides above-mentioned a number of scales appear in researches. There are a scale of activity of S. Yasar [37], a scale a cyberloafing of behavior of E. Orucu and H. Yildiz [38], a scale of cognitive absorption of Z. Genc and S. B. Tozkoparan [39], the questionnaire of Time Banditry Questionnaire [18].

It is possible to draw a conclusion that researchers actively work on creation of reliable and valid tools for studying of prevalence of a cyberloafing in business and in the academic sphere. Some of them develop own scales, others adapt and reconsider already existing, check their reliability and validity on respondents from the different countries. We did not manage to find cyberloafing research techniques in Russian. The lack of the reliable tool significantly complicates a cyberloafing research in Rossi. Therefore, adaptation of the scale offered Y. Akbulut, etc. on Russian-language selection became an objective of this research. 


\section{Research Methods}

Studying of an opportunity of application of the scale of cyberloafing offered Y. Akbulut, etc. in researches of school students from Russia was carried out in the Ural region. 30 items of a scale were translated into Russian. The preliminary text of the questionnaire was submitted to the 2 experts who estimated its compliance to the studied phenomenon and understanding for school students. As a result one item was excluded. Responses were rated on a 5 -point Likert scale, $1=$ never, 2 =rarely, $3=$ occasionally, $4=$ frequently, $5=$ every time.

School students who spent vacation at a summer children's camp, answered questions of total option of a scale. Only 150 people at the age of 13-15 years participated in a research (63 men; 84 female).

All analyses performed in this study were conducted using the Statistical Package for the Social Sciences (SPSS) version 23.0.

\section{Findings}

The main purpose of performing exploratory factor analysis is to identify the underlying structure among the variables. In this present study, Bartlett's test of sphericity is significant $(\mathrm{p}<0.0001)$, and the Kaiser-Meyer-Olkin measure of sampling adequacy is 0.862 , which is far higher than 0.6 as the cut-point [2], suggesting the data is suitable and appropriate for factor analysis. Next, principle component analysis was chosen as the method of factor extraction using an orthogonal rotation of varimax on the data to determine the underlying factor structure and to evaluate the construct validity of Y. Akbulut et al. cyberloafing scale.

By evaluating the eigenvalues and by observing the scree plot, five factors were retained, which accounted for $63.7 \%$ of the total variance of the scale, reaching a satisfactory level. The criteria used to extract the factors were according to: Keiser's criterion (eigenvalue must begreater than 1); The loading score for each item $>0.4$; Factors must have not less than 3 items loaded. The factor structure is similar to Y. Akbulut et al. [24] and K. Kian-Yeik [2] consisting of five subdimensions of cyberloafing. Among the 29 existing items, three items ( $\mathrm{Gg} 1, \mathrm{Gg} 2$, So7) were deleted from the scale. The internal consistency of each factor is assessed through Cronbach's alpha $(\alpha)$ method. The method of splitting of the test showed that between answers to even and odd points there is a significant correlation $\left(\mathrm{r}_{\mathrm{s}}=0.932 ; \mathrm{p}=0.001\right)$.

The first factor united 6 items of a scale of online shopping (So, $\alpha=0.881$ ). The second factor included items of a scale of accessing online content (Aoc, $\alpha=0.867$ ). The third factor united 5 items of a scale real-time updating (Rtu, $\alpha=0.839$ ). The fourth factor united bigger number of points from a scale of sharing ( $\mathrm{Sa}, \alpha=0.813$ ). The fifth factor included three points of a scale of interchange devoted to interaction with friends $(\alpha=0.775)$.

Table 1 shows prevalence of a cyberloafing among participants of a research. Most often at lessons school students accessing online content and sharing with friends.

Difference of this structure of a cyberloafing from the structure presented in researches of other authors is the lack of a factor " gaming or gambling ". According to our data those questions which are presented in a scale of Y. Akbulut et al. do not allow to estimate game activity of children at a lesson. Three questions which were included into the Russianlanguage version of a scale showed the low level of reliability $(\alpha=0.645)$. We assume that it is necessary for Russian-speaking audience essential to change this items. For example, to include in it point concerning games on electronic devices during a lesson. It makes sense to exclude such points as job search and visit of the websites with gamblings in general. In 
general, the developed option of a scale has rather high internal validity and reliability, but needs transformation.

Table 1. Assessing of use of the Internet for personal reasons at lessons at school.

\begin{tabular}{|l|c|c|c|c|c|}
\hline \multicolumn{1}{|c|}{ factors } & Minimum & Maximum & Mean & Skewness & Kurtosis \\
\hline online shopping & 1.00 & 4.83 & 2.0 & 0.998 & -0.112 \\
\hline accessing online content & 1.00 & 5.00 & 3.1 & -0.290 & -0.932 \\
\hline real-time updating & 1.00 & 5.00 & 2.7 & 0.051 & -0.897 \\
\hline sharing & 1.00 & 4.83 & 2.0 & 1.308 & 2.129 \\
\hline sharing with friends & 1.00 & 5.33 & 3.4 & -0.680 & -0.320 \\
\hline
\end{tabular}

\section{Conclusion}

Results of a research showed that the offered Russian-speaking option of a scale cyberloafing needs completion. It is necessary to reconsider a scale of gaming of pupils at a lesson. The fact that for school students interaction with friends represents an independent factor of cyberloafing is important too.

This work makes a contribution to studying of cyberloafing among school students in Russia. Further we plan to finish cyberloafing scale for school students and also to check possibilities of its use among students of higher educational institutions in Russia.

\section{References}

1. N.V. Sivrikova, D.Yu. Berezhnaya, Siberian journal of psychology, 60, 166-180 (2016)

2. K. Kian-Yeik, Pertanika J. Soc. Sci. \& Hum., 26 (1), 409-424 (2018)

3. Y.R. Chassiakos, J. Radesky, D. Christakis, M. A. Moreno, C. Cross, Pediatrics, 138 (5), e20162593 (2016)

4. H.K. Kabali, M.M. Irigoyen, R. Nunez-Davis, J.G. Budacki, S.H. Mohanty, K.P. Leister, R.L. Bonner, Pediatrics, 136(6), 1044-1050 (2015)

5. S. Weeden, B. Cooke, M. McVey, Journal of research on technology in education, 45(3), 249-262 (2013)

6. D.O. Koroleva, Psychological science and education, 20(1), 28-37 (2015)

7. C.T. Hsin, M.C. Li, C.C. Tsai, Educational Technology and Society, 17(4), 85-99 (2014)

8. N.V. Sivrikova, E.M. Harlanova, E.A. Stolbova, A.A. Ageev, Dilemas contemporaneos-educacion politica y valores, 108, (2019)

9. G. Durak, International review of research in open and distributed learning, 18(1), 84108 (2017)

10. F. Sana, F. Weston, N.J. Cepeda, Computers and Education, 62, 24-31 (2013)

11. J. Wu, W. Mei, J. C. Ugrin, Cyberpsychology, Behavior, and Social Networking, 21(3) (2018)

12. M.R.R. Gallego, A.L. Martinez, I.M. Herrera, Pixel-Bit- Revista De Medios Y Educacion, 50, 77-93 (2017) 
13. V.K.G. Lim, Journal of Organizational Behavior, 23(5), 675-694 (2002)

14. B. K. Mercado, C. Giordano, S. Dilchert, Career Development International, 22(5), 546-564 (2017)

15. G.W. Bock, S. Park, Y. Zhang, Journal of Computer Information Systems, 50(3), 150163 (2010)

16. K. Koay, P. Soh, K. Chew, Management Research Review, 40(9), 1025-1038 (2017)

17. N. Derin, S.G. Gökçe, Procedia - Social and Behavioral Sciences, 235, 694-700 (2016)

18. E. Lowe-Calverley, R. Grieve, Cyberpsychology: Journal of Psychosocial Research on Cyberspace, 11(2), 5 (2017).

19. J.C. Ugrin, J.M. Pearson, S.M. Nickle, Journal of Internet Commerce, 17(1), 46-63, (2018)

20. L. Khansa, R. Barkhi, S. Ray, Z. Davis, Inf Technol Manag, 19(4), 197-215 (2018)

21. S. Pindek, A. Krajcevska, P.E. Spector, Computers in Human Behavior, 86, 147-152 (2018)

22. H.Y. Durak, M. Saritepeci, The Social Science Journal, 56(1), 69-87 (2019)

23. M. Saleh, I. Daqqa, M.B. AbdulRahim, N. Sakallah, International journal of advanced and applied sciences, 5(4), 87-92 (2018)

24. Y. Akbulut, Ö. Ö. Dursun, O. Dönmez, Y. L. Sahina, Computers in Human Behavior, 55, 616-625 (2016)

25. S. Yasar, H. Yurdugul, Social and Behavioral Sciences, 83, 600-604 (2013)

26. Ş. Gökçearslan, Ç. Uluyol, S. Şahin, Children and Youth Services Review, 91, 47-54 (2018)

27. F. Varol, E. Yıldırım, Technology, Knowledge and Learning, 24(1), 129-142 (2019)

28. R. Yılmaz, H. Yurdugül, Journal of Computing in Higher Education, 30, 530 (2018)

29. F.G.K. Yılmaz, R. Yılmaz, H.T. Öztürk, B.Sezer, T. Karademir, Computers in Human Behavior, 45, 290-298 (2015)

30. I.B. Arabaci, The Turkish Online Journal of Educational Technology, 16(1), 72-82 (2017)

31. L. Yuwanto, Psychology Research, 8(4), 173-177 (2018)

32. Y. Akbulut, O. Dönmez, Ö. Ö. Dursun, Computers in Human Behavior, 72, 87-95 (2017)

33. E. Ergun, A. Altun, Egitim Teknolojisi Kuram ve Uygulama, 2(1), 36-53 (2012)

34. V.K.G. Lim, T.S.H. Teo, Information and Management, 42, 1081-1093 (2005)

35. T.K. Coskun, S. Gokcearslan, World Journal on Educational Technology: Current Issues, 11(1), 94-103 (2019)

36. A.L. Blanchard, C.A. Henle, Computers in Human Behavior, 24, 1067-1084 (2008)

37. S. Yasar, H. Yurdugul, Procedia-Social and Behavioral Sciences, 83 (2013)

38. E. Orucu, H. Yildiz, Ege Akademik Bakis, 14(1), 99-114 (2014)

39. Genc, Z. \& Tozkoparan, S. B. Firat Universitesi Sosyal Bilimler Dergisi, 27(1), 53-61 (2017) 